\title{
THE CHALLENGES OF OFFSHORING AND OUTSOURCING
}

\author{
M. Stojanov \\ Economics and Management of Commerce Department, University Of Economics, Varna, Bulgaria
}

\begin{abstract}
The impact of global economic uncertainty on every business agent is a driver in searching for alternatives to allocate resources, which allow obtaining the expected return and risk management of the economic process. With the business model of outsourcing and offshoring, organizations receive suitable tool for managing company resources and optimizing the quality of their business processes. The main purpose of this paper is to review the positives and negatives of outsourcing and offshoring, to summarize some of the factors and the trends determining the formation of Bulgaria as a destination for this business model. The continuous development of outsourcing and offshoring and the associated advantages and disadvantages with them can be a factor in the competitiveness of modern business at regional, national and global level.
\end{abstract}

Key words: outsourcing business model, offshoring business model, risk transfer.

\section{INTRODUCTION}

The global economy, based on the rules of equality of the participants in the economic process, is a source of economic growth. In an open-source system, resources should find alternative solutions for allocation based on the optimum of expected return and risk. In this way, business agents motivated by their own optimization goals solve the problems of restrictive conditions by directing their resources to countries and regions with better business conditions. This mechanism is at the heart of the business model of offshoring at international level and outsourcing at national level.

Undoubtedly, the economy of the new millennium originates and forms the sustainability of development on the basis of the vast amount of information and scientific knowledge that society has access to and use in its economic activity and social life. Together, they are a driver of entrepreneurship and competitiveness, which is the basis for them to be perceived as "a strategic goal for the European Union to become the most competitive and dynamic knowledge-based economy in the world" (1), which creates conditions and forms priorities "to a state of smart, sustainable and inclusive growth" (2). Thus, knowledge and information as valuable resources can be drivers of economic development and prosperity on a regional, national and global scale. Therefore, any business model that effectively exploits these resources allow for optimal economic and social outcomes for the benefit of company and society as a whole. Thus the business concept of outsourcing that successfully exploits this approach demonstrates great success and, by offshoring, its global popularity.

The main aim of the present study is to review the positives and negatives of outsourcing and offshoring, to summarize some of the factors of this business phenomenon and the trends determining the expected development and formation of the country as a destination for this business model.

In its essence, this paper does not attempt to give and overestimate the economic significance of outsourcing and offshoring, but without doubt their supporters emphasize their potential for efficiency gains, optimization of costs and tax benefits that are achieved in local, regional and global aspect of the economic agents applying this business models.

\section{TEORETICAL FRAMEWORK}

Outsourcing is "perhaps as old as commerce itself and serves as the foundation for any relationship where one person performs an activity on behalf of another" (3). Therefore, whenever an independent business agent engages an external contractor or outsourcer to carry out activities and processes, it is outsourcing. When the outsourcing of activities or processes takes place in another country, we 
are talking about offshoring. It is linked to the cross-border direction, where participants are economic entities positioned in two sovereign states. The main economic incentives derive from the opportunity for participants to take advantage of the open systems where the resource orientation is attracted by better conditions for carrying out certain activities or processes across borders. Reasons for such business behavior may be varied but are mainly related to approaching the source of demand; the proximity to resources that are being used; the lower cost of the resources used and mainly the labor benefits associated with the applicable tax system, etc.

Traditionally, outsourcing is tied to the transfer of risk and utility between participants that interact on the basis of an agreement reached. One party transfers certain activities that are conditionally insignificant to its typical business activity and the other party takes responsibility for their professional performance. This relative release is linked to the clear definition of performance requirements, which in most situations lead to an improvement in the quality of the outsourcing activities. Adherence to a precisely defined standard is a source of long-term relationship and satisfaction of the participants. The basis of success of offshoring are the economic effects associated with "labor cost reduction (LCR), ... achieving higher quality of services and using qualified workforce, ... the developed infrastructure, reliable telecommunication network, economic and political stability, legal and tax system" (4). Furthermore, "in times of crisis - it is defined as one of the most adequate management approaches for the sustainable development of many organizations" (5). Areas of application of outsourcing are extremely broad, and can be both a highly specialized activity and typical day-to-day or periodic maintenance and service business operations. Thus, outsourcing reveals new opportunities for stimulating entrepreneurial activity, mainly in the areas of: transport, security, customer service, training, maintenance services, canteens, construction, healthcare, utilities, facility management, etc. At the same time, the competition among outsourcing companies can trigger optimization of the cost of the proposed performance of the activities, but improvements in quality are much more serious. The latter is a projection of the economic motivation of the contractor to reproduce for the longest possible period his contractual relationship, which is the objective basis for the scale of the activities and the related expectations of the contracting assignor. Like other business activities today, the use of outsourcing is a business standard and is applied in most modern companies. It is an external service that is part of the understanding of entrepreneurship, which seems to be an inherent element in the start-up of any business. Its popular or widespread use is related to activities and processes such as (6): information provision, distribution, personnel, accounting and legal services, construction and repair, safety and security, warehousing, maintenance and cleaning of premises, marketing activities, catering, etc. Hence, each type of outsourcing service is an element of the normal understanding of a modern business that focuses on the creative and innovative potential of the core business. Therefore, outsourcing is a strategy to combat wasteful business and low-cost allocation of scarce resources.

At the same time, this is also a strategy whereby the economic agent improves his position in the business ecosystem in which it exists. Through such interaction between outsourcing participants, reciprocal and rational transmission and resource transformation takes place. As this process of relationship will persists until a certain external factor does not affect the participants and the effectiveness of the performance. This determines the switching nature of outsourcing where benefits are formed for both parties, or the outsourcing arrangement is a "win-win strategy". The main consideration behind this assumption is the elimination of compromises related to the accomplishment of the assigned tasks. This is determined by the "outsourcing mechanism that is related to the formulation of tasks by the guarantor (client) without specifying the approach to their solution" (7), but unconditionally the implementation should be as rationally and economically as possible effective for both sides. The preconceptions behind outsourcing are that client loses operational adaptation in the implementation process and the fundamental goal of performance is the extreme cost reduction and the price of the arrangement. Such limited understanding links outsourcing as an end-toend approach and an easy solution to cost castration that is achievable in the vicious circle of systemic compromise solutions and the pursuit of success in the short term. Then, behind successful outsourcing, priority must be given to the innovative implementation of the activities and processes that meet defined quality criteria. This means that modern outsourcing is an effective solution for 
performing traditional processes and activities in a way that matches expectations or even improves performance. Consequently, the field of outsourced activities will continuously expand in the course of increasing scientific knowledge. In this way, technological and information innovations that form the scientific human development are the main driving forces for expanding the scope of outsourcing in today's business. Moreover, global openness and comprehensive dissemination of knowledge allow successful regional models to be adapted at national and global levels and vice versa, thus outsourcing is becoming the "best business practice that is necessary to stay competitive and achieve success in the current environment" (8) and turns it into "the greatest business discovery in recent decades" (9).

\section{OUTSORCING AND OFFSHORING BENEFITS AND DISADVANTAGES}

The whole diversity of activities that may be subject to outsourcing has as its primary objective the pursuit of the following diverse economic and social effects:

- optimizing the costs associated with these activities due to the fact that a complex price is paid for execution by an external economic agent and through competitive negotiation the best conditions of outsourcing services can be achieved. The most significant saving is accomplished in relation to the costs of employees who are in a working relationship with the external contractor. In this situation, the achievement of relative savings in laborrelated costs is simultaneously linked to improving labor productivity. This is true both for own staff who specializes and focuses on the fulfillment of his core work commitments as well as for the employees of the outsourcing company who perform only the delegated job tasks;

- lowering the costs of creating the end product when performance of certain activities and processes is performed at a better value by the external organization, this leads to a decrease in cost. The economic logic of this relationship is linked to the achievement of greater efficiency in the execution of certain activities by an outsourcer compared to their own realization by the firm;

- improving the quality of the created end product, if it production depends on the quality of the additional and accompanying outsource activities;

- reducing unnecessary operational decisions that are within the competence of the outsourcer and concentrating on the organization and management of the core business. In regard to this, the recipient of the outsourcing service relies on the expertise of the respective contractor, which can be of great benefit in terms of optimizing processes and activities. At the same time, by transferring additional activities and concentrating on the essence of core processes, it allows businesses to develop and improve their competitiveness;

- saving time in terms of strictly setting execution deadlines that an outsider should comply with or, if not, incur sanctions at a predetermined amount;

- tax benefits related to the full recognition of outsourcing costs for corporate income tax purposes, which reduces the amount of taxable profits;

- decrease or total elimination of the extra costs related to fines due to non-observance of systematically changing regulatory requirements. It is assumed that the specialized outsourcing company maintains its competence in relation to the activity carried out and any omissions may be entirely on its own account, unless otherwise agreed between the parties, etc.

In addition, offshoring, due to the overseas specificity of outsourcing, has the following advantages over conventional contract out:

- taking advantage of facilitations of local labor law legislation and a more liberal regime for managing it. In this way, a company that can affords the transfer of cross-border enforcement activities actually seeks countries where labor policies and regulations are not severely restrictive or those that are considerably more liberal than national legislation. By doing so, the company provides the comfort to operate in a more favorable environment, which ultimately improves its competitiveness in its own country;

- the offshore companies, preferred to attract diverse employees by nationality, motivated by incentives such as flexible employment and pay, not the availability of labor legislation and collective bodies to protect their interests. This can sometimes be a source of labor disputes to be influenced by the specifications of applicable judicial system and legislation;

- we take into account the differences in culture, the common linguistic and educational level of the employed in offshore, due to national characteristics and individual abilities as a possible positive and in some situations negative aspect of offshoring. We associate a similar situation 
with the transfer of corporate identity and image between the participants in the agreement. Using such convergence, the host country can adopts innovative practices, business traditions and corporate culture, which is extremely beneficial;

- offshoring has an extremely strong impact on economically more underdeveloped countries and regions where it can create a significant contribution to reducing unemployment and generating economic growth and income. Moreover, for a large part of the transnational companies offshoring is the only expansionary strategy that allows to maintain competitive positions, etc.

Individually or simultaneously, each of the possible outcomes of the outsourcing agreement can be fairly accurately established by applying the benchmarking approach before and after the introduction of this business model. We should also point out that the business model of outsourcing is applicable to all types of organizations, regardless of the scale of their business. Its application becomes important after an objective comparison of the costs of its own execution with the price of outsourcing. However, this does not mean that the decision should be aligned solely on the directly related costs, but also on the indirect costs, which are sometimes subject to a difficult quantitative demarcation and commitment to a particular activity. Moreover, outside the scope of objective evaluations are resources related to time and entrepreneurial resources or the value of alternative costs.

If the activity allows, it is perfectly possible to involve two participants simultaneously for the selection of an outsourcing contractor. If it is not possible to organize such a project, it can take place in two successive test periods. In this way, the company will ensure that it will conclude the long-term relationship with the better outsourcing agent.

Controversial is the assessment of the beneficial effects of offshoring for the participating countries and they are linked to the excessive use of resources in a less developed and highly dependent economy. The main consideration in this polemic is the transfer of profit to the source and the owner of the capital, the exploitation of the weaknesses of local legislation, corruption practices, the shadow economy, the exploitation of the factors of production, the neglect of the environmental effects of the activity, etc. In this way, the strength of a participant, especially when it is a transnational company, can cause a change in equality and proportional partnership agreements and lead to defects in the market system. This is because their power at the local, national and global levels distort the independence and objectivity of the regulatory mechanism and the ability to influence local and central authorities through abusive and informal practices. Also, the main reason for migration to outsourcing or offshoring is sometimes underestimated or overestimated. This most often means that the initial values of the applicable agreement is sometimes accompanied with hidden costs for both parties, leading to the need to renegotiate the conditions in the implementation phase of the agreement. Conversely, for some of the participants, these hidden costs will lead to a failure to meet expectations of economic performance and efficiency.

Significantly negative from the application of outsourcing in the company is the problem of identifying external employees with the corporate values and the ability to fit into the work atmosphere of their own team. It is possible that under certain circumstances the employees of the service company may have limited access or reversely to benefits from their free access and cause unfavorable situations and consequences. In certain situations, the behavior of an outsourcing company that serves many clients may not be in the context of a loyal partner and as supplier acting with due commercial care, and the ranking of priorities in executing client requests will lead to a conditional underestimation of some and the raising of other partners in subjective order.

Normally, at a certain scale of activity, and again motivated by the economic interest of the leading participant, the reverse mechanism of returning processes and activities also takes place. Moreover, when global development achieves the convergence of economic conditions between countries, the reversal process of reshoring is normally started. At its core, along with microeconomic considerations, are the fundamental factors of the economic environment, such as labor cost, price levels, national currency stability, accessibility and prices of energy resources, etc. And if, at the time of the offshore initiative, they were the main motivators for the global movement of entrepreneurship, then at a later stage they were gradually losing their significance. Such a trend means that in the world there are systemic prerequisites for carrying out a global migration of outsourcing destinations. On the one hand, besides the 
economic incentives to look for efficiency, today, in the conditions of economic instability, the striving for better risk management is also more important. This means that through the diversification of outsourcing destinations companies can achieve improved utility to risk ratio. One possible approach is positioning close to consumer demand, which guarantees extended opportunities to respond to its volatility. It is almost certain that at a future moment when a company is able to form recognition and value of its brand, it can go totally to outsourcing the entire business. Thus, the company will only continue to manage its business globally as a successful and beautiful shell, while the actual implementation of processes and activities will be successfully transferred to contractually bind loyal and successfully controlled outsourcers. The main commitment remains the brand's support and corporate image and the skillful delegation of rights and obligations to the contractor. In this model, there is always a serious risk that the outsourcer will have enough experience and entrepreneurial confidence to launch his own brand and business to replace the trustee.

\section{BULGARIA DESTINATION \\ AS OUTSORCING}

The announcement of Bulgaria by the European Commission for a functioning market economy in 2002 and the subsequent full EU membership since 2007 makes the country a prosperous outsourcing and offshore destination within Europe. According to the complex evaluation of A. T. Kearney through the Global Services Location Index, Bulgaria managed to occupy 15 th position in 2005,9 in 2007 and 2014, 13 in 2009, 17 in 2011 and according to the latest ranking of the index in 2016, Bulgaria is ranked 12th out of 55 countries included in the most recent tracking of attractiveness for global outsourcing and offshoring (Figure 1).

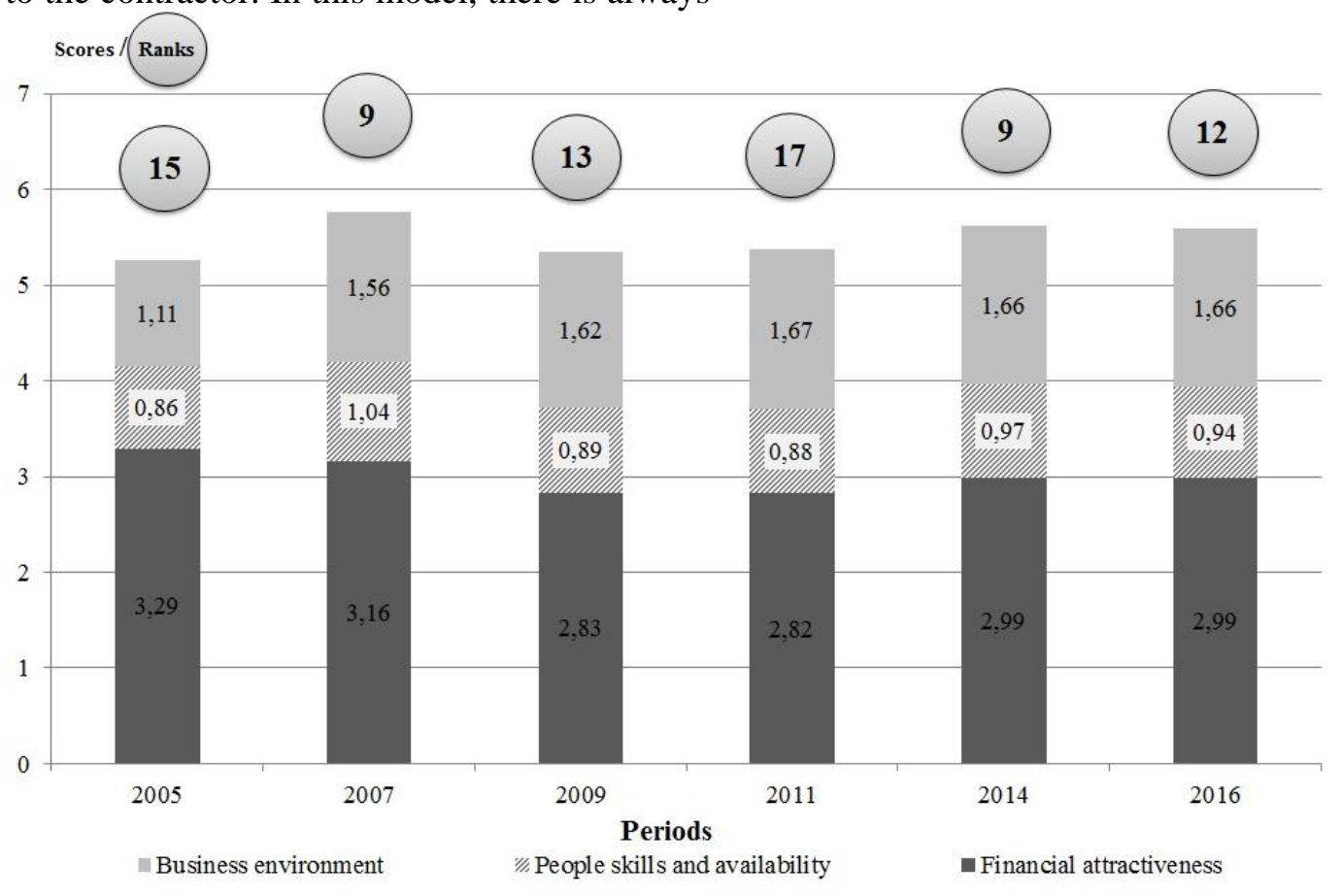

Figure 1. Position (the rank is in the circle) and structure of Global Services Location Index of Bulgaria in the ranking of A. Т. Kearney for 2005, 2007, 2009, 2011, 2014 и 2016. Source: A. Т. Kearney Global Services Location Index Reports, 2005, 2007, 2009, 2011, 2014, 2016, <https:/www.atkearney.com/strategic-it/globalservices-location-index> (29.04.2017).

Over the years, changes in GSLI structural elements for Bulgaria indicate which factors are the forces for bringing the country to the top of the global ranking. On first place of importance are the conditions of the business environment and the second place is the financial attraction of the country. The first group of business environment factors account for $30 \%$ of the overall assessment and is associated with its relative stability in the regional dimension of its geographic location in the heart of the Balkans (as a relatively stable macroeconomic framework and political environment), the existence of a labor factor in certain sectors with appropriate skills and competencies, improvement of the quality of infrastructure (transport corridors, quality of telecommunication services provided, etc.) and the availability of adaptation to the global influences of the legislation in the field of 
intellectual property protection. The second group of financial attractiveness factors account for $40 \%$ of the overall assessment of the index and are directly expressed by the relative attractiveness of the Bulgarian economy in terms of compensation for the labor factor, stimulating taxation for business units and the stability of the national currency within the context of the currency board framework.

\section{CONCLUSION}

In such a situation, "overall improving of the conditions for outsourcing in the country will positively influence the competitive environment" (7) and will have a positive effects on the whole economy and society. At this stage, Bulgaria has the real opportunity to be able to derive the positives from this business phenomenon and to position itself as an attractive destination for outsourcing and offshoring on a regional and global scale.

\section{REFERENCES}

1. Decision No 1298/2008 / EC of the European Parliament and of the Council. Official Journal of the European Union, L 340/84, BG, 32008D1298, (6), 19.12.2008 (in Bulgarian).

2. Council Recommendation (EU) 2015/1184. Official Journal of the European Union, L 192/27, BG, (3), 18.7.2015 (in Bulgarian).

3. Amant, St. K. Examining IT outsourcing: An overview. Understanding IT
STOJANOV M.

outsourcing: A perspective for managers and decision makers, IGI Global, pp. xxxiilix, 31.07.2009.

4. Harizanova, M. Offshoring of Human Resources - a Factor for the Formation of the World Labor Market. // Economic Alternatives, UNWE, 5:11-25, 2008 (in Bulgarian).

5. Harizanova, M. Outsourcing: Role, characteristics and directions of application. Scientific papers of UNWE, Sofia, 2:7-39, 2012 (in Bulgarian).

6. Bozhinova, K. Challenges to the Commercial Enterprise in the Use of Outsourcing. Collection of papers from the International Scientific Conference "Regional and Global Dimensions of Trade", Varna: Science and Economics, pp. 467-476, 2013 (in Bulgarian).

7. Zhelyazkova, D. Requirements for application of outsourcing in distribution. "Izvestiya" Journal of the University of Economics - Varna, 1:108-123 2011 (in Bulgarian).

8. Murray, J. Promise of A-76: Does efficiency translate to readiness? In 2003 Logistics Dimensions (Air Force Logistics Management Agency), Diane Publishing, December, pp. 126-148, 2002.

9. Anikin, B., A. and I. L. Rudaya. Outsourcing and Outstaffing: All Technology Management. Moscow: INFRA-M, 2009 (in Russian). 